Full reference: Potter, J. (2005). "'This brings back a lot of memories" - A case study in the analysis of digital video production by young learners." Education, Communication \& Information 5(1) pp. 5-23 ISSN 1463-631X print; 1470-6725 online/05/010005-19

\title{
"This brings back a lot of memories" - A case study in the analysis of digital video production by young learners
}

\author{
John Potter, \\ Goldsmiths College \\ J.Potter@gold.ac.uk
}

\begin{abstract}
This paper discusses a three and a half minute video written, shot and edited by two eleven year old children in London in the summer of 2003. Key questions which were used to structure the discussion included the following: When the children work in a school setting in a medium which is culturally closer to their experiences of life outside than is usual within the curriculum, how do they choose to represent themselves? Which aspects of their lives and/or media experiences do they employ and in which modes? How are these choices related to the meanings they wish to convey? Which aspects of the form and function of digital video authoring allow the children to move the locus of control of activities closer to themselves? What does a discussion of these issues tell us about possible future directions in researching young learners' digital video production? Frameworks for analysing the piece were drawn from emerging theories of multimodal literacy, from studies of ICT in Education and from work on media production by young people. Some conclusions were drawn about the position of the work in relation to existing models of curriculum activity in the light of the range of sophisticated and rich representations made by the children in their media text.
\end{abstract}

\section{Introduction}

Digital video editing software and hardware allows relatively low cost access to the means of producing and editing moving image texts. As they become available in schools, sophisticated cameras and computer based editing solutions are beginning to place control of a medium of contemporary mass communication and production in the hands of young learners. This technology has started to find a place in schools in the UK in work across the different age phases, led by practitioners and advisors. It has attracted the attention of BECTA, the agency which records and disseminates innovative practice in schools with ICT. A pilot study and report on digital video work across the curriculum in 50 schools is available (Reid, Burn et al. 2002). At the same time, manufacturers of low cost and user friendly digital video solutions have positioned themselves in the education market, promoting a range of possible curriculum and cross-curriculum activities in schools (Apple 2003). 
Beyond what it may add to teaching and learning in the various subjects and subject traditions, perhaps the most interesting aspects of the work with digital video by young learners are the ways in which the medium can be employed in an expressive and culturally authentic mode. The phrase "culturally authentic" in this context refers to the fact that children working with digital video equipment are operating in a medium which is familiar and central to their everyday experiences of contemporary modes of communication. Alongside this, it is "expressive" in the sense that children can now work as authors in a medium in which they are more usually positioned as consumers. Children can, depending on the parameters of the particular project, be encouraged to move the locus of the control of the experience closer to themselves. However, describing what happens when such tools are in the hands of such young learners is relatively complex. It requires the synthesis of a range of inter-disciplinary models drawn from the theoretical discourses of multimodal theory, cultural, film and media studies. Some writers working in the field draw these discourses and knowledge domains together and map out the terrain of a possible "grammar of the moving image" (Burn and Parker 2001). It is with these frameworks and positions in mind that the work reported in this article has been analysed.

The video described and analysed in this article was made in the summer of 2003 by two children aged 11 in an inner city state primary school in south -east London. Their media text was written, shot and edited while they were in their final year at primary school, just before they left and went their separate ways to their respective secondary schools. The children were taking part in a project which gave them the opportunity to create a piece of digital video which would celebrate their time at primary school and represent aspects of their experience of one phase of their life before embarking on a new one. The article seeks to report on their video activity using a framework through which to examine not only the choices which the two filmmakers made but also the features of the medium which were critical for the learners in moving the locus of control closer to them.

The particular video under discussion lasts for three minutes and thirty-five seconds. Within this relatively short time frame, there is ample evidence of the sophistication of these manipulators of moving image literacy as they merge sound, image, cultural references and performance into a representation and celebration of their identity at a particular place and time. It will be instructive to consider which features of the technology as well as the learning situation provided them with the means to represent their experiences in this way.

\section{School contexts}

In order to understand further the unusual nature of the freedom the children had to work in school in this way, it is worth noting one or two key aspects of the wider socio-educational context against which the work was produced. The process of transition from one phase of education to another in England at the time of writing is 
dominated by Standardised Assessment Tasks (SATS). Children take these tests in their final year at school, at the age of 11 in year 6 of the English educational system. The results of these SATS are used to provide indicators of school performance which are publicly reported. Overall performance of a year group in the SATS assumes huge significance because they are used to compare one school with another. They have come to dominate the curriculum offering in the final year of primary schooling In such a context, many children are focussed for much of their final year on a relatively narrow set of competencies and performance outcomes in a narrow range of curriculum subjects (HMI/OFSTED 2001). They do not always have the opportunity to produce a range of texts, reflect and express their feelings, for example, about leaving. However, when the SATS are completed, there is a period of up to eight weeks before the school year ends and the children actually have to leave. Within this time frame it becomes possible to enter a different mode of being in a school and it is in June and July each year that special projects can be situated which push back the boundaries of the curriculum and allow children to explore different modes of expression and production. In some cases this takes the form of a leavers' show or an exhibition of work. For the children at the school under discussion here, the opportunity arose for them to make a compilation video about themselves in selfchosen groups and pairings. The whole class made videos for the compilation and the work described is only one of ten pieces produced.

Finally, although the children were operating outside of the usual set of curriculum activities for their age group, it is true to say that they were still acting under some constraints. Time, for example, was an issue (as it is for most filmmakers shooting to a deadline). Access to the camera was another occasional problem (unlike most filmmakers). They were further asked to limit their production to a short sequence (the brief was to work to about five minutes worth of screen time in the final video). However, there were no action limitations on narrative, structure, or content (beyond the unstated acceptance of school norms on offensive language or behaviour). The two boys whose work is in the study had control of all of these factors.

\section{Written artefacts versus digital artefacts}

Our understanding of the more usual modes of creating texts has a long tradition. When children first learn to write, one of the moments of greatest significance for them is the realisation that there is something they can create that will stand in their place when they are not there. They learn that their inscription on a page will convey information from them or about them to an audience which is not necessarily present at the time the words are put onto the page (Bissex 1980; Whitehead 2002). As they grow older within the education system they learn to refine this process, to communicate with greater complexity in different genres to different audiences and to apply the conventions of literacy (Beard 1993; Bereiter and Scardamalia 1993). At school and in other sites of learning, as they grow older, they become sophisticated manipulators of words by practising craft skills and learning to express themselves in response to feedback, either in the form of an assessment dialogue with a teacher or with a peer, parent or carer. Most of the curriculum assessment for written literacy is 
directed at how pieces of writing have been shaped and at which craft skills and surface features reveal most about a child's academic performance and attainment.

The analysis of writing by children draws on a shared discourse around the development of written English, albeit one whose values and assumptions are regularly contested by those in the political-educational arena including parents, teachers, children, carers, academics, politicians and writers. Whatever the disagreements, written literacy is debated in an area which is well mapped.

On the other hand, the literacies around the production of media texts by children in school are at the beginning stages of being described and explored. Writers are having to employ different theoretical models in creating the vocabulary to describe both the media texts and the processes. For an analysis of work with moving images, "Multimodal theory", as proposed and described by Gunther Kress and others is an important frame of reference because it takes account of how meaning is embodied, constructed and communicated through the multiple possibilities of gesture, movement, sound, images, speech and text (Kress and Van Leeuwen 2001).

Recently, an account of a model for analysis of media texts has been made by Andrew Burn and David Parker. This draws partly on multimodal theory and relates it, amongst other things, to an analysis of children's computer games and websites as well as to their media output (Burn and Parker 2003). This provides a possible model for looking at the media text in question and it is this model which forms the basis of the scene by scene discussion of Leo and Stephen's video below.

Within the emerging frames of reference and theoretical perspectives outlined, the analysis of video reported here was concerned with how digital inscription comes to be created, produced and edited in such a way that it stands for the authors when they are no longer there. There were a series of overarching and interrelated questions:

When the children work in a school setting in a medium which is culturally closer to their experiences of life outside than is usual within the curriculum, how do they choose to represent themselves?

Which aspects of their lives and/or media experiences do they employ and in which modes? How are these choices related to the meanings they wish to convey?

Which aspects of the form and function of digital video authoring allow the children to move the locus of control of activities closer to themselves?

What does a discussion of these issues tell us about possible future directions in researching young learners' digital video production?

\section{Control of the production: features of planning and equipment used}

A key concept attached to analysis of media production cited by Burn and Parker and articulated in multimodal theory is the notion of Distribution. The line drawn between design and production is eroded in a process which allows for such rapid 
transformations, transmission and re-assemblages of distributed media (Burn and Parker 2003). The aspects of control and design in the production discussed here were key in allowing the two children to present and re-present themselves in a number of different roles, in a number of different but interwoven discourses.

Leo and Stephen's video was one of the shortest pieces produced but it took the longest amount of time to complete, edited with great attention to detail. It was a series of visual jokes and comedy sketches which celebrated their friendship and their time at the school. As will be seen, the video operated at a number of different levels of complexity and in a number of different modes. Before proceeding with the scene by scene analysis, it is worth noting some of those complex features of the production, from planning, through shooting to editing, which were brought under the direct control of the children.

The initial planning was conducted a few days in advance of the shooting. The children were asked to map their approaches to the project in the form of a "mind map" on A3 paper. They placed their names in the centre of the page and drew web diagrams of all of the options they would like to consider and all the features they would like to include. In this way, some early indications of their conceptions of the possibilities of the medium were elicited. The use of concept mapping as a tool of analysis is gaining ground in the study of ICT in Education (Mavers, Somekh et al. 2002), particularly in the light of the data generated by their use in the IMPACT2 study in England (Harrison, Comber et al. 2002). In this case, Leo and Stephen were revealed as already aware of the potential of the medium, in particular of properties of soundtrack manipulation and the framing of camera shots to create illusions and visual jokes.

A further conceptual leap came when they began to realise their ideas in linear form. Information from the maps was transferred to a grid which was known to the children as a "storyboard" (similar to but not strictly a film-maker's storyboard) which included space for adding sound files or commentary. In fact, as David Buckingham has pointed out, children often confuse a storyboard with a comic strip anyway and its importance as a planning tool with younger children is diminished, until they actually start to use the camera (Buckingham 2003). There were, in fact, some changes and additions during the project. In the scene by scene discussion below, which also draws on an interview with the children afterwards, there are instances of adaptation and some very interesting comments are made about the personification and even embodiment of the camera itself.

In spite of the changes that were made, the overall adherence to the linear schematic reveals how, in the earliest stages, Leo and Stephen had a clear idea of how they wished to proceed. Their planning shows awareness of the possibilities of the medium for rapidly assembling ideas from a range of sources, using their shared knowledge of media literacy and cultural reference points. In other words, they had a vision from the outset of how they might employ their shared awareness of the discourse. An illustration is provided of Leo and Stephen's linear plan in figure 1 below: 

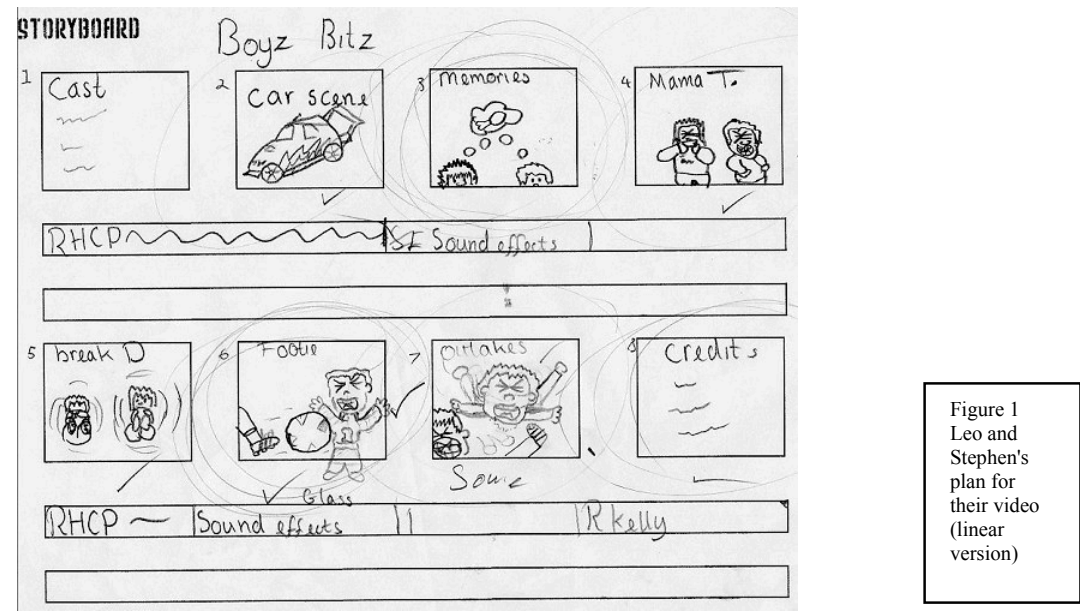

In the interview afterwards, the boys had this to say about the necessity of the planning process:

Stephen: ... if you just did it (without planning sheets), it would be...

Leo: ...rubbish. We planned on these sheets.

You had these little boxes... and we had this diary book...

Leo and Stephen decided that it would be "rubbish" without the planning. It is possible that, within the discourse around the video itself, the two boys were positioning themselves as being compliant and happy with being made to plan the project rather than to start shooting straight away. However, placing the planning and the finished product side by side reveals the presence of early and detailed markers for the key elements, scope and reach of their project. It became a working document for the two boys concerned and was, in fact, markedly different from many of the others produced which varied greatly in their usefulness to the final outcome.

On the equipment side, the cameras which were used allowed the children to record with ease straight to digital video tape, in the mini-DV format. Material which was recorded could be reviewed on location on the LCD side panel on the camera. It was then downloaded for editing on a laptop computer. This process was carried out by the children themselves, controlled from the computer within a "Capture" interface, before proceeding through "Editing" to "Make Movie". Pinnacle Studio 8, running in Windows XP, was the editing software used in the project.

The software provided the children with a user-friendly interface, allowing them to take control of many aspects of the finished product, including all of the following elements:

a The ordering of the clips

a The transition between the clips

a The use of sound, including the importing of sound effects in the form of a library of wave files

- The use of a narrative voice, to be added later if required

a The soundtrack, including excerpts from their chosen CDs 
a The titling (including the use of visual effects and rollovers)

Figure 2 shows the relevant software workspace used during the video project. A timeline is clearly visible with clips loaded and options available for titling and sound effects below. Once Leo and Stephen had the camera in their hands and were assembling the piece, alternative possibilities would present themselves and the camera itself would assume a role. And once inside the editing space on the computer screen, the potential to re-design and re-assemble their intentions within a range of discourses became possible.

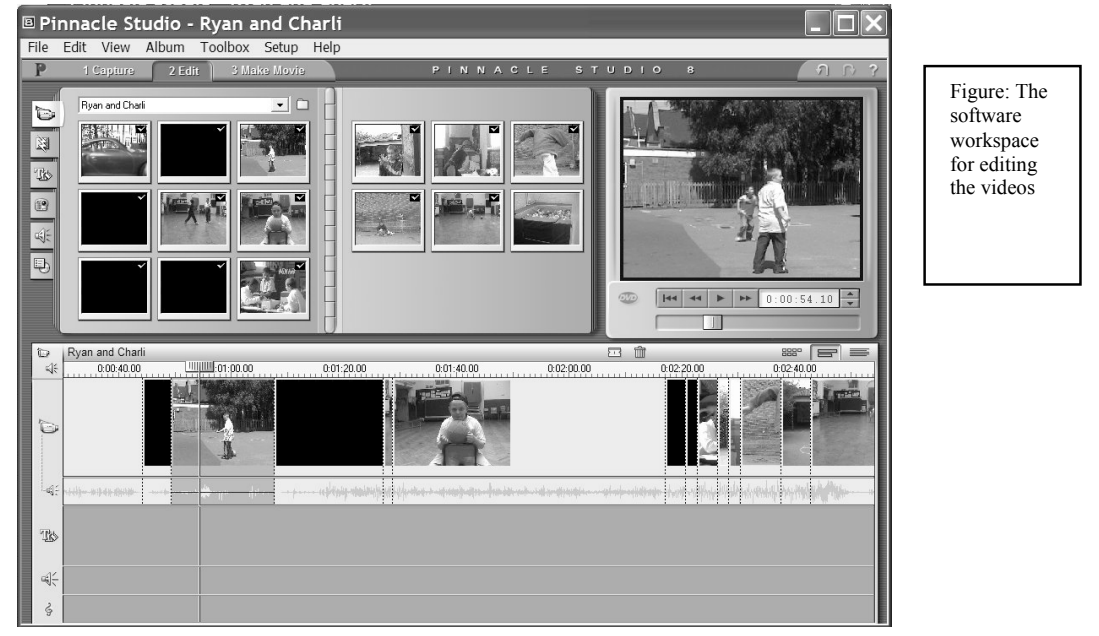

\section{Scene by scene through the video}

Leo and Stephen's video drew on a wide range of reference points which dipped freely into and out of popular media culture (The Matrix movie, the Johnny Vaughn Show TV show, the music of the White Stripes and so on) as well as to reference points from their own past (A previous school assembly, their role in the class as comedians and so on).

\section{Scene 1 - "That's a lovely Porsche Boxster" 00:00:00 - 00:14:14}

In the opening shot, Stephen is some distance away from the camera but apparently sitting in the driving seat of a car and being questioned about it, where he got it from and how much he paid for it. From behind the camera, Leo asks him for the details, gets an answer, moves the car and it is revealed as a toy being held up to the camera. The dialogue runs as follows:

Leo (Behind the camera) Hello Stephen

Stephen Oh hello Leo

Leo Oh That's a lovely Porsche Boxster 
Stephen It's beautiful innit? Beautiful...

Leo How much was it?

Stephen About three quid

Leo Where'd ye get it?

Stephen Round the sweetshop (pause to deliver the punchline)...it's a fakey...

Leo No - eeeeergh (Makes car skidding noise and pulls it away from the camera, revealing Stephen standing by the school fence)
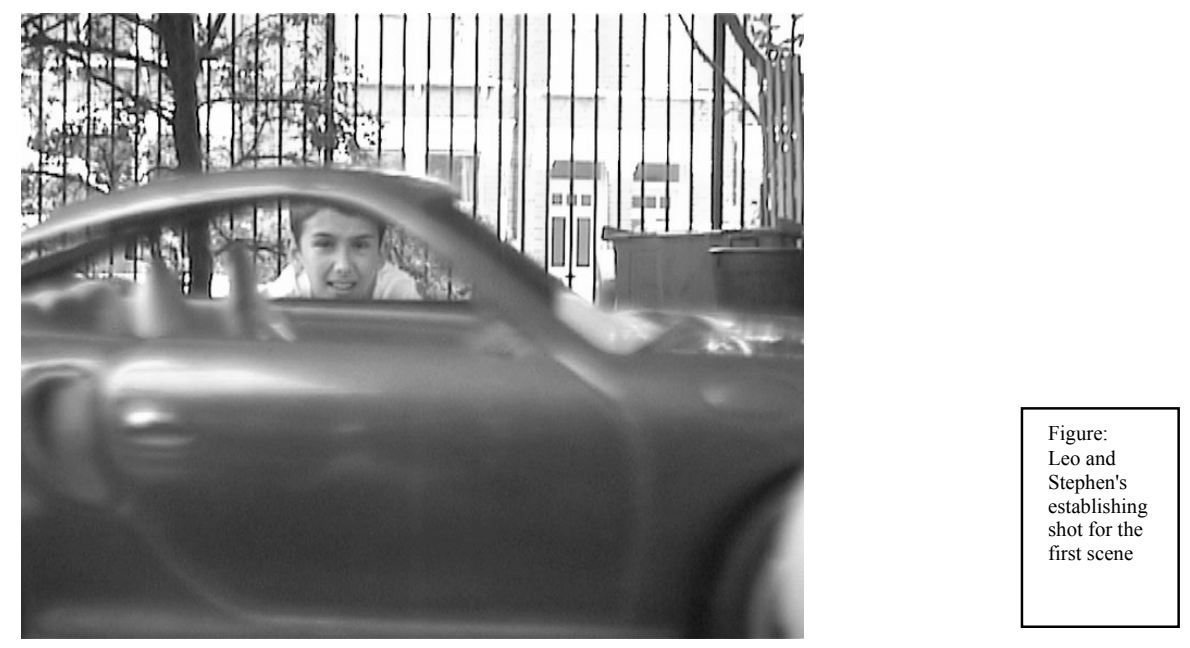

The opening 14 seconds establish the tone and structure of the whole production. It is a striking and funny scene which announces the main themes of the media text. It makes explicit the idea that Leo and Stephen are going to be fully in their socially constructed role as class comedians. It is clear from the opening shot that they wish to manipulate the medium in such a way that they are represented "in role", at the last opportunity to make a statement about their time at the school.

As revealed later in an interview with the two boys, the foreshortening joke comes from the popular TV show "You've Been Framed" which features accidents, jokes and stunts recorded by members of the public. In fact, so certain were they that this joke would work, they planned to use this technique again at a later stage in the video (see below in scenes 5a and 5b).

By the close of the opening scene, we have information about the discourses within which meaning will be made. The audience knows that Leo and Stephen will be playing themselves as the class knows them, driving the project forward with pace and with humour. They also know that they will use models drawn from media culture (the foreshortening joke and also the satirical take on the interview to camera). At the same time the roles of the two protagonists in relation to each other have been delineated. Stephen is in shot but some distance away. Leo is behind the camera but his voice is louder. The fact that he is not in shot is compensated for by the status 
conferred on him as interviewer and director and announced by the louder voice. These roles, as will be seen, were to be reversed in the fifth scene of the project.

\section{Scene 2: "Mama took those batteries"-0:00:14:15 - 0:0045:05}

The second scene sees the boys positioned side by side in the centre of the shot in front of a mural at the school. This scene operates at many different levels and in many different modes, related to the discourses within which they occur. Gunther Kress and Theo Van Leeuwen define discourse as "socially constructed knowledges of (some aspect of) reality" (Kress and Van Leeuwen 2001). The discourses in this scene are rooted specifically in the shared knowledge and cultural experience of Leo and Stephen's class inside and outside school. Not only do they tap into the shared experience of past events in the school but also they cast the net of references into the shared cultural experience of an episode of the Simpsons. Both are significant to members of the immediate audience for the piece and both are interwoven to produce the meaning required for this particular project.

Firstly, in terms of reference to the shared cultural history of the class, in an earlier year group, year 4, Leo and Stephen performed a song together which remained part of the folklore of the class. It was well known as a shared memory and occurred in the earliest draft of their linear plan for inclusion in the video (see the fourth frame in figure 1). The choice of situation, in front of a mural painted by the class in an earlier year was also a signifier of a recalling of times gone by.

In terms of shared experience of media culture, the song also happened to be their own version of a blues song composed in "the Simpsons" by Bart Simpson in which he protested at his mother, Marge, removing his computer game batteries. This became "Mama took those batteries" instead of "Marge took those batteries". In this class, as in many others, the Simpsons were something of a touchstone and much of the play referred to episodes from the series.

This easy manipulation of reference points from their own past and their own media experiences was typical of their piece and added a further layer of structural complexity. They knew that their audience would be able to recognise both in what they had done.

There is a further mode to consider which helped to define the position of the boys in relation to class members. Not only were they two of the acknowledged comedians in the class, they also had their own musical choices to make. The musical form chosen by the boys for their song in the video - and in year 4 - was the 12-bar blues, complete with a mimed harmonica part. This chimed in with their choice of music for the soundtrack and was a powerful indicator of their individuality. This form of music was, perhaps, also considered by the boys as being somehow adult, or semiadult, in nature and, as well as demarcating them from the remainder of the class, 
suggested an "otherness" in terms of style and outlook. By far the majority of the class were interested in the more familiar pop music of the culture. The hit of the summer was by R Kelly (Ignition - Remix) and was featured in all but a few of the other video clips. If they dipped at all into the past, the other videos borrowed a few seconds here and there from Michael Jackson. Leo and Stephen's musical choices at this point and elsewhere reflected their "otherness" both in approach and choice of soundtrack. "Mama took those batteries" was the first white pop blues on the soundtrack and it was to be followed later by borrowings from CDs by the "Red Hot Chilli Peppers" and "the White Stripes".

\section{Scene 3: "This brings back a lot of memories"-0:00:45:06 - 0:00:52:00}

A scene which lasts seven seconds follows the blues song. Up to this point, the Leo and Stephen had signalled that they were going to play with the format, that they were going to use it to express cultural differences and make resonances with shared discourses within the class. In this very short segment, they show that they are also capable of gently mocking the whole process of the video itself. They sit by the mural in a window seat. Both boys, but with Leo dominant on the soundtrack, put on the voice of an elderly person saying, "this brings back a lot of memories". This bridging sequence is significant with both of them in shot and both of them clearly in control. They seek to bridge the gap between themselves and the overarching purpose of the video piece. By mocking the whole process of making memories in this way, on camera, they assert their control of the whole authoring process. They further indicate their participation yet separateness from the rest of the class.

\section{Scene 4: Breaking the window-0:00:52:00 - 0:00:58:21}

This Scene showed both boys playing football in the middle foreground and appearing to break a window. Leo, with his back to the camera, passes the ball to Stephen who kicks it out of the shot and to the right. The sound of the breaking glass was added from the software library. The boys then both run away.

This episode has several reference points. The preferred activity of all the boys and many of the girls in the class was playing football in the area shown. Placing themselves in that place at the heart of the video underlines their place in that class at that particular moment. However, they are operating within their own previously announced constructed roles of class comedians. The visual gag that they represent is the breaking of the glass out of camera shot. It recalls a kind of humour which belongs in an earlier era (a bit like their preference for older musical forms) perhaps from "the Beano" or other popular but anachronistic comic reference points.

The measurement of the breaking glass onto precisely the right point on the soundtrack raises the prospect of the possibilities of the ICT directing and affecting the outcome. Both boys are taking part in a project which has allowed an editing suite to be created in their classroom. The normal curriculum is suspended and they can spend time working on their finished video. They are taking part in a wider process 
with its own discourse. They know that there are possibilities within the software which will allow them to generate events "after the event". This is what they have done in "breaking the glass". They have bent their product slightly out of shape in the interests of further exploring the process. Stephen Heppell and others see this as the most exciting yet frequently ignored potential of ICTs for use in classrooms (Heppell 2001). We can see from the first minute that the potential is realised in this particular production with the two boys able to control and assemble their work in a variety of styles, situated within a number of overarching discourses in a range of modalities.

\section{Scene 5a and 5b: Show off-the gorilla fight - 0:00:58:21 - 0:01:18:00}

In this Scene Leo fights with a toy gorilla and the foreshortening joke is revisited (see figure 4). Stephen holds a toy gorilla in front of the camera in the foreground of the shot. Leo stands at the back of the hall appearing to be hit by the gorilla and hitting it back. Effects were added live (Stephen's fighting noises into the camera microphone) and afterwards (a sharp blow, added from the software library, again the boys realising their decisions by looking in the library of possibilities within the software).

For this sequence, as noted above, the roles are reversed. There is an interesting counterpoint to the allocation of roles in scene one. Stephen is behind the camera and Leo is in front of it. Stephen gets to make the comment in the final section of the scene. He reveals the joke by throwing the gorilla the length of the hall and calling out "Show off!" to Leo who makes a comedy fall.

\section{Scene 6: Basketball, break dancing and hall sequence with soundtrack 0:01:18:00 - 0:01:31:00}

The opening of this scene sees Stephen spinning on his back directly from the fade out of Leo spinning on his back in the scene above.

This Scene, taken from the planning directly, incorporated breakdancing and basketball moves. Many of the videos, particularly from the boys, featured these cultural reference points, alongside football and R Kelly. However, the choice of the music was, again, distinct, drawing not from the expected tradition (hip hop, rap etc.) but from the boys' preferred musical form - the white pop blues - as espoused by the Red Hot Chilli Peppers (see the note of this in the original planning in figure 1 - the music being shown as RHCP).

\section{Scene 7: Johnny Vaughn Show 0:01:31:00 - 0:02:19:00}

A long "Johnny Vaughn" interview follows with Leo slipping between a straightforward impersonation and a variety of accents. The whole scene is ad-libbed between the two performers (both commenting "I didn't know you was going to do that..." in interviews afterwards). This scene is also notable for comments later in the interviews about how the camera gives you ideas. Asked whether using the camera had, in itself, given them any ideas for changing things while filming, this is what they had to say:

Stephen: It gives you ideas...in the end we had more ideas... 
Leo: I don't know how you say it. It didn't like give us ideas like (pause) it talks to you ... it gave us ideas like what you could do with it

Stephen: He changed his voice ... I didn’t even know you was going to do that.

At one point the camera adopts the persona of Donald Duck and nods at the interviewer. In this case the camera appears to be a character in the video itself. It is almost as though it was interjecting itself into the process, freeing the boys to improvise within the overall construction. Later in the article, the playfulness and fluidity of possible roles will be discussed in relation to practice with digital video.

During this scene Leo and Stephen maintained their place in the discourses established in the previous settings and discussed above (summarised perhaps as media-aware class comedians). The range of accents used by Leo, slipping from a South London accent into a kind of Irish accent, draws on the seamless shifting of roles in playground discourse. It also references presenters who slip between roles in popular television programmes, featuring, for example, impressionists such as Alistair McGowan (featured in the UK on BBC TV).

Their role in the social discourse of the class is explored in the closing of this Scene by Leo attacking the camera who he says is "blanking" him. Sometimes disputes are solved in this way in the playground and this reference point was particularly strong with the audience when they comprised the boys' peers.

Scene 8: White Stripes Video: The Matrix, titles, glimpses of classmates 0:02:19:00 - 0:02:53:00

This scene adopts a different form, that of the music video (employing the more fashionable blues of The White Stripes: 7 Nation Army). Small segments of clips around the classroom and school appear with the action soundtracked throughout. This is the first time that the boys choose to write on screen, naming some of their classmates and the classteacher.

This is also significant as the first time that they appear as themselves. They are on the soundtrack, captured on the camera microphone in a separate sound file celebrating Stephen's version of the Matrix. At the most extreme reference point from popular culture (mimicking the special effects from the Matrix at a fraction of the cost, by Stephen running up a wall), they choose to present themselves to the audience as knowing auteurs. They emphasise their "otherness" again accompanied by the music of the White Stripes. 
Scene 9: This brings back a lot of memories: Out-take sequence 0:02:53:00 0:03:01:00

Leo and Stephen made virtually no mistakes in any takes. Yet they were anxious to honour the tradition of the out-take, which is often added to the ends of videos and tacked onto DVD. At this level they were at one with the discourse of popular culture. They filmed a number of different versions of this scene but decided to incorporate Stephen getting the voicing of the line "wrong" when he says: "This brings back a lot of memories." This recalls the third scene above and recapitulates all of the previously discussed elements, namely, the "otherness" the boys feel. They proceed to play fight on camera and there is a fade to the end title sequence.

\section{Scene 10: Can't stop - End title sequence 0:03:01:00 - 0:03:35:00}

This scene references the ending of the film "Dumb and Dumber" where the two characters walk away from the camera, pushing each other as they go. They disappear out of shot and then reappear running back towards the camera with a few seconds from "Can't Stop" by the Red Hot Chilli Peppers playing. The titles run through almost the whole of this Scene and thank the teacher and the project coordinator "For letting us do this". The concession to permission having been granted for the boys to play and experiment in an otherwise structured and prescribed setting is revealing and sets the videos apart from the world of the normal classroom. The locus of control has shifted towards the learners and they recognise that they have been given power and responsibility in their roles as writers and directors. As the introduction finishes and the first words of the song are sung, the video ends. This ending is placed right on "Can't stop" and is the last of a series of perfectly timed visual jokes. They stop, and the whole video ends, just as the lead vocal sings, "Can't stop". See the illustration of the final frame in Figure 5.

\section{Returning to the questions}

The first overarching question raised about this work was this: When the children work in a school setting in a medium which is culturally closer than is usual to their experiences of life outside, how do they choose to represent themselves?

Leo and Stephen chose to exploit the multimodal and multi-textual nature of the medium, the flexibility and provisionality of the ICT tools to represent themselves in a number of available discourses. Throughout the production, they emerged as writerdirectors with a concern for entertaining themselves and others, drawing on cultural reference points from cinema and television, but always within many different modes at the same time.

In the third scene, they put themselves into the frame, cast as commentators on the whole process of re-making memory in digital format, gently mocking the format. This was the first instance of being able to position themselves as "others", outside of the usual practice within the project, as satirists and slightly older, wiser and capable of seeing the bigger picture. 
The second question asked: Which aspects of their lives and/or media experiences do they employ and in which modes? How are these choices related to the meanings they wish to convey?

Leo and Stephen chose to represent themselves simultaneously as adventurous exploiters of opportunity within the medium, capable of appropriating design and form from other productions. Within the social discourse around the making of the video, they clearly wanted to be seen as directors. In the project interviews at the close of the videomaking, they behaved in the manner of writer-directors, interviewed on television, adopting the same poses and taking on two distinct roles. Stephen was serious and polite, Leo interacted throughout with the camera, joking and winking at it.

On another issue, in one brief scene, Leo and Stephen chose to satirise the whole process, yet they fulfilled the brief of the project, which was to commemorate their time at the school in some way. They chose to represent themselves in the way that the rest of the class knew them, in the socially constructed role as class comedians. More than this, they chose to represent themselves as visual comedians who could manipulate the media available to them fitting them to the project parameters and quoting a range of representational artefacts.

In addition, remembering that the video was intended to be part of the transition process from primary education into secondary education, Leo and Stephen frequently took the opportunities provided by the project to show themselves as ready to move on, as in some way different to the "others". They used musical forms which were not part of the norm in terms of musical appreciation, but were part of an older age group's experience. They stepped outside of the production to mock it (albeit gently). They gave a great deal of thought to the sophisticated design features they wished to exploit, from framing shots, to placing sound on the soundtrack with the highest degree of accuracy.

The third question asked: Which aspects of the form and function of digital video authoring allow the children to move the locus of control of activities closer to themselves?

With regard to their feelings about the ICTs used (the cameras, CDs, software and hardware etc.), their comments in the interview afterwards were interesting because they affirmed their faith in ICT as something that allows continual rethinking and revision. Asked if they were happy with the outcome or if they would change 
anything, they stated that if it had turned out "boring" they wouldn't have worried because they could rub the whole thing out and start again from the beginning.

Watching them at work in the editing process revealed that they were impressed by, and anxious to incorporate as many of, the available features of the editing software specifically:

a Wiping (swift humorous transitions which gave pace and shape to much of the project)

- Adding music from personal CDs (which underlined the emphasis on modes which expressed identity and choice in the project)

- Keeping and mixing in sound captured from the camera (which allowed them to refer to the project within the project - e.g. the Matrix reference)

- Adding titles (which, though minimally used in this project compared to others in the video, further stamped their identity on the video)

- Adding sound effects (Correctly allocated to places on the soundtrack, these became significant in the construction of many of the scenes, as noted in the various sections above)

\section{What implications are there from work of this kind?}

\section{ICT and digital media production}

Avril Loveless identifies those aspects of digital technology which allow for "creative" activity to take place. One of those she describes is "Collaboration" in which ICT work with others allows the construction of "shared knowledge" (Loveless 2002). She cites Csikszentmihalyi's systems model of creativity as interaction between people within specific domains and contexts which give rise to the production of work but also construct the value of that work (Csikszentmihalyi 1996). The features within the software listed above indicate that, for the children concerned, the ICT tools provided the means of production and interaction. Leo and Stephen's video piece arises out of these sets of circumstances, a particular time-delimited context, a set of shared values and a validation of their work. This is at the intersection with the framework provided by multimodal theory where discourse, rather than domain, is the term used to anchor the analysis of the outcomes.

During the work, the processes which are important to these outcomes are those which allow for the collaboration between the two performer-directors, because their relationship with each other and to their socially constructed role is at the heart of what they are producing. The aspect of collaboration in media authoring by children is addressed by David Buckingham in his discussion of the social worlds of media production (Buckingham 2003). Here we see that what is important is the taking on of specific roles within the video itself. The fluid nature of these roles is interesting in the context of Leo and Stephen's video. Here are two children who know each other really well, working in a new medium, under pressure of time, observed by peers, using new technology to present their previously established roles within the world of 
the classroom alongside new material which shows them as manipulators of the genre. The process is undertaken in such a way that, at any given time, either one of them can be in role as a performer, a writer, a camera operator, a producer or a director.

\section{Play and digital video}

A further factor in the discourse around the videos is the notion of play. In what sense could the terms playful or playfulness be used about the boys' output in this project? Early years educators understand the value of play and talk as a mode for expressing literacy and moving into decentred forms of expression (Whitehead 1997; Smidt 1998). Later, the curriculum downgrades play and drama in the formal setting and more acceptable forms of literacy which can be more easily assimilated into formal assessment programmes become the norm. It continues in the realm of oracy in the playground and in the inner speech of childhood which some educators have shown can be unlocked in performance and move children into less formal, more culturally expressive literacy (Rosen 1989). Here, the performance unlocked by the digital drama, as it is enacted, results in an outpouring of play from outside of the classroom curriculum, from the discourse of the playground and the language and gesture of contemporary media.

Two senses in which play functions in the context of learners working in a digital medium are discussed by John Carroll (Carroll 2002). First, there is the sense in which the mutable status of the medium allows those involved to assume different roles quickly, to reject the idea of a "unitary self". Role playing which changes from moment to moment is a feature of Leo and Stephen's work. The scene in which Leo changes from "Johnny Vaughn" into someone with a completely different accent and cultural reference point is playing with the possibilities of multiple identities. In three and half minutes Leo and Stephen engage in the morphing possibilities of the medium, they play, amongst other characters, a comedian, a voiceover artist, an old person, a break dancer, a basketball player, a chat show host, the characters from Dumb and Dumber, Neo from the Matrix, and two blues singers. At all times, beneath the surface of the video they are themselves and, occasionally, as seen above, they intervene to remind the audience that they know this (See discussion of scene 8 above).

Carroll also discusses young people's work in digital drama as lying on a continuum from regulated play to unregulated, anarchic play. The medium allows Leo and Stephen to operate along this line and to move between various points on it throughout the video, in much the same way as it allows for the changes in representation. From the moment they mock the whole process in scene 3 ("This brings back a lot of memories") through to the moments where they pretend to break the glass while playing football they indulge in these forms of play. It never quite reaches the extremes of unregulated, anarchic play, except possibly in the section where the Johnny Vaughn interview breaks down (Stephen was surprised when this happened, as noted above, saying later in an interview "I didn't know you was going to do that".) Leo and Stephen's role within the class was as class humorists not as anarchists and their apparently unregulated play falls within accepted forms of behaviour. 


\section{Final thoughts}

John Cuthell characterises young learners working with ICT tools as "bricoleurs", capable of using ICT to give "an account of their lives in a world where allusion, reference and quotation seem the only possibility" (Cuthell 2002). The process of assembling the video, quoting reference points from contemporary culture as well as drawing on references from their own past is what sets this medium and its associated tools apart from other activities traditionally associated with the school curriculum. It raises the possibility of ICT equipment of this kind playing a part in re-engineering the curriculum. Essentially, to borrow terms from Zuboff's "In the age of the smart machine", when we analyse young people's work with digital video we see that are not working with tools which automate existing processes, we are dealing with tools which work with meanings and ideas in new ways (Zuboff 1988; November 2001).

Research in the field of digital video editing by young learners is located at the intersection of different theoretical positions on ICT in Education, Multimodal literacy and Cultural \& Media Studies. This article has presented a case study of digital video editing by young learners which draws on those traditions. It has attempted to describe the range of sophisticated discourses within which the children were operating as well as the craft skills of digital video editing and production which they employed. These operant discourses and skill sets are not necessarily recognised or valued within current curriculum and assessment models. Nevertheless, the three and a half minutes of video examined demonstrate that working in this medium allows rich areas of children's personal, cultural and media experience to be explored and re-presented in innovative and sophisticated ways. Further research will attempt to refine the description of the processes involved and develop the necessary theoretical frameworks, fully cognisant of the possibilities afforded by the medium for curriculum change.

\section{BIBLIOGRAPHY}

Apple (2003). Apple Education Lesson Plans, Apple Education. http://www.apple.com/uk/education/

Beard, R., Ed. (1993). Teaching literacy, balancing perspectives, London: Hodder \& Stoughton.

Bereiter, C. and M. Scardamalia (1993). Composing and Writing. Teaching Literacy, Balancing Perspectives. R. Beard, London: Hodder \& Stoughton: $155-175$.

Bissex, G. (1980). GNYS AT WRK: A child learns to write and read, Cambridge, MA: Harvard University Press.

Buckingham, D. (2003). Media Education: literacy, learning and contemporary culture, Cambridge: Polity.

Burn, A. and D. Parker (2001). "Making your mark: Digital inscription, animation and a new visual semiotic." Education, Communication \& Information 1(2) 
Burn, A. and D. Parker (2003). Analysing Media Texts, London \& New York: Continuum.

Carroll, J. (2002). "Digital Drama: a Snapshot of evolving forms." Melbourne Studies in Education 43(2): 130-141

Csikszentmihalyi, M. (1996). Creativity: Flow and the Psychology and Discovery of Invention. New York: Harper Collins.

Cuthell, J. (2002). Virtual Learning: The impact of ICT on the way young people work and learn, Aldershot: Ashgate,

Harrison, C., C. Comber, et al. (2002). ImpaCT2: The Impact of Information and Communication Technologies

on Pupil Learning and Attainment, London: DFES,.

Heppell, S. (2001). Preface to ICT, Pedagogy \& the Curriculum. ICT, Pedagogy \& the Curriculum: Subject to change. A. Loveless and V. Ellis. London: Routledge Falmer

HMI/OFSTED (2001). Annual Report of Her Majesty's Chief Inspector of Schools, London: OFSTED.

Kress, G. and T. Van Leeuwen (2001). Multimodal Discourse: The modes and media of contemporary communication, London: Arnold.

Loveless, A. (2002). Literature Review in Creativity, New Technologies and Learning, 36, Bristol: NESTA Futurelab,

Mavers, D., B. Somekh, et al. (2002). "Interpreting the externalised images of pupils' conceptions of ICT: methods of analysis of concept maps." Computers and Education 38: 187-207

November, A. (2001). Empowering Students with Technology, New York: Skylight Professional Development.

Reid, M., A. Burn, et al. (2002). Evaluation Report of the Becta Digital Video Pilot

Project, Coventry/London: BECTA/BFI: 92.

Rosen, M. (1989). Did I hear you write?, London: Andre Deutsch.

Smidt, S. (1998). A Guide to Early Years Practice, London: Routledge Falmer

Whitehead, M. (1997). Language and Literacy in the Early Years, London: Paul Chapman.

Whitehead, M. (2002). Developing language and literacy with young children, London: Paul Chapman.

Zuboff, S. (1988). In the age of the smart machine: The future of work and power. New York: Basic Books. 